that it may be related to eriodictyol rhamnoside ${ }^{\circ}$, it has an activity of about $0 \cdot 2$ that of rutin. On a weight basis it is less than half as active.

Pomiferin and gossypol were tested, but were too insoluble. Catechol, hydroquinone and resorcinol accelerated the destruction of epinephrine.

The most active compound was gossypetin, a flavone with an activity $16 \cdot 0$ times that of rutin (on a weight basis). This was followed closely by $3,3^{\prime}, 4^{\prime}$-trihydroxyflavone $(15 \cdot 5)$ and quercetin $(10 \cdot 0)$.

The results are in accord with the activity series reported by Lavollay?, who used a similar method. The most active of the seven compounds he tested was quercetin. Lavollay ${ }^{8}$ also showed by manometric and colorimetric methods that the autoxidation in vitro of epinephrine was inhibited more by quercetin than by rutin or rhamnetin, and that naringin had low activity. $\mathrm{He}$ and his co-workers claimed a close parallelism between the results obtained by the smooth muscle assay and those by the autoxidation studies in vitro. Using an improvement of his colorimetric method, we could not confirm this parallelism in a more extensive series of compounds tested.

The present study shows that the common struccapable of forming complexes with heavy metals; tural feature of the active substances is a grouping and for those pairs of substances with closely similar structures, the more active forms a more stable complex. Although many of the active substances contain the ortho-dihydroxybenzene nucleus, this structural element does not appear to be a necessary condition for activity, since 8-hydroxyquinoline, 3-hydroxy-3',4'-dimethoxyflavone and 5-hydroxyflavone show activity in varying degree. (Bartleti', working in these laboratories, has indicated that inhibition of succinoxidase by $2^{\prime}, 3,4$-trihydroxychalcone is due to quinone inhibition of sulphhydryl groups and that quinoid effects on proteins in general, of related ortho-dihydroxybenzene compounds, should be borne in mind in biological studies of these compounds. When the o-dihydroxy groupings were substituted (for example, methylated), no inhibition occurred, presumably because the quinoid structure could not form. However, in the body, it is conceivable that phenyletherase activity could cleave the carbon-oxygen bond of phenyl ethers, and thus, for example, demethylate hesperidin derivatives ${ }^{10}$.) The presence of a potential chelate-forming grouping, on the other hand, is not a sufficient condition for activity, since hesperidin, hesperetin, phloridzin and $2^{\prime}$-hydroxychalcone show negligible activity; yet the first two of these have been shown by polarographic studies to chelate readily with copper ${ }^{11}$.

A conspicuous result of this study is the demonstration that there is no correspondence between the reported biological and clinical activity of many of these compounds on capillary fragility and their activity in this assay. It is evident that the studies should be extended to the intact animal in further attempts to relate sympathomimetic action and capillary fragility. Experiments in this direction are under way in these laboratories.

A complete report of these studies will be given elsewhere.

This investigation was supported by grents from the California Fruit Growers' Exchange, U.S. Public Health Service, Roche Anniversary Foundation, and S. B. Penick. We are indebted to Prof. T. R. Seshadri for generously supplying several of the most active compounds. We also wish to thank Prof. J. Lavollay and Dr. G. Valdecasas for their many informative comnounications.

1 Javillier, M., and Lavollay, J., Helv. Chim. Acta, 29, 1283 (1946). Parrot, J., Gaz. Med., 53, 157 (1946). Géro, E., Bull. Soc. Sci. Hyg. Aliment., 34, 85 (1946).

${ }^{2}$ Parrot, J., and Galmiche, P., Bull. Med., 59, 413 (1945). Galmiche, P., "La résistance et la perméabilité des vaisseaux capillaires et "Introducion al éstudio de la vitamina P", (Miguei Suset, P. P.. lona, 1945). Munro, $\mathrm{N}$. Lazarus, $\mathrm{S}$, and Bell, $\mathrm{G}$. BarceAbst. and Rev., 17, 291 (1947).

${ }^{3}$ Bacq, Z. M., Arch. Internat. Physiol., 42, 340 (1936) and 44, 15 (1936). Clark, A. J., and Raventos, J., Quart. J. Exp. Physiol. $29,185(1939)$

4 Wilson, R. H., Mortarotti, T. G., and De Eds, F., J. Pharm. Exp. Therap., 90, 120 (1947).

'5riedenwald, J. S., and Buschke, W., Amer. J. Physiol., 140, 367 (1943).

- Mager, A., Z. physiol. Chem., 274, 109 (1942).

'Lavollay, J., C.R. Soc. Biol., 135, 1193 (1941).

${ }^{8}$ Lavollay, J., "I. L'autoxydation des diphénols, en particulier de l'adrénaline. II. Structure et role fonctionnel de la vitamine P' (Hermann et Cie., Paris, 1943).

- Bartlett, G. R., Fed. Proc., 7, 6 (1948); J. Pharm. Exp. Therap. 93, 329 (1948)

${ }^{10}$ Huggins, C., Jensen, E. V., and Cleveland, A. S., Proc. Soc. Exp. Biol. and Med., 68, 477 (1948).

11 Geissman, R. A., and Friess, S. L. (unpublished work).

\section{TRAWLING SURVEYS IN PATAGONIAN WATERS}

$T$ HROUGHOUT the whole of the cold-temperate (sub-Antaretic) zone of the southern hemisphere the waters overlying the Patagonian continental shelf provide the largest expanse of sea shallow enough to support a considerable population of commercial fishes. During the years 1927, 1928 and 1931-32 the Discovery Committee's research vessel William Scoresby carried out three trawling surveys of this region between latitudes $42^{\circ} \mathrm{S}$. and $52^{\circ} \mathrm{S}$. The primary object of the investigations was to provide information upon which the prospects of carrying on a commercial fishery from the Falkland Islands could be assessed. The results of these surveys have now been published in a scientific report* of considerable importance by Dr. T. John Hart, biologist on the Discovery Committee's scientific staff. Dr. Hart did not himself carry out the surveys (though he has had some experience of field-work in that region), and the results have been written up mainly from manuscripts left by the late E. R. Gunther who, unfortunately, did not live to complete them. In these circumstances the task of picking up the threads and collating the data involved much difficulty, and Dr. Hart often found it necessary to start afresh from the original data. The substance of the report is therefore the combined work of Gunther and Hart, but the latter has written the entire text in its final form.

The first part of the report is devoted to the general topography of the shelf, with sections on hydrology and plankton. The Patagonian continental shelf stretches from the River Plate in the north to Staten Island in the south, and extends off-shore to an average distance of some 200 miles to the eastward. There are uniformly moderate depths over the plain of the shelf with a very easy depth gradient from the $80 \mathrm{~m}$. to the $200 \mathrm{~m}$. contour which may be taken

* Discovery Reports. Issued by the Discovery Committee, Colonial Office, London, on behalf of the Government of the Dependencies of the Falkland Islands. Vol. 23. Report on Trawling Surveys on the Patagonian Continental Shelf, compiled mainly from Manuscripts left by the late E. R. Gunther. By Dr. T. John Hart. Pp. 223-408. (Cambridge: At the University Press, 1946.) 35s. net. 
as outlining the shelf 'edge' beyond which the descent to oceanic depths is relatively abrupt. Rough ground with 'corallines' and coarse deposits prevails in the southern part of the area surveyed, while finer deposits are present farther north, providing better conditions for trawling. The main current affecting the area is the relatively cold Falkland current flowing from south to north, and coldest along its off-shore margin. The warm Brazil current impinges upon this, offshore, in the extreme north-east of the area, where the hydrological conditions may be very complex; but they are normally too far out to affect conditions on the shelf to any important extent. On the inshore flank of the Falkland current (which is a movement of sub-Antarctic surface water) the flow is less strong, so that 'old shelf water' is warmed and sometimes even flows southward as a small intermittent counter-current close in to the land. This seems to have an important effect on the distribution and movements of some of the fishes. The annual cycle of surface temperatures is centred lower than in corresponding latitudes in the northern hemisphere, with the peak after mid-summer, and the annual range is small. At greater depths the temperature range is still smaller and the time-lag between air and sea temperatures is even greater, so that bottom temperatures are highest in autumn and lowest in spring or even early summer.

Some preliminary observations on plankton are discussed, but the large collections obtained have not yet been worked up. The same is true of the benthos. Nevertheless, some fairly firm conclusions have emerged. The general facies of the plankton is closely similar to that found in cold-temperate waters in other parts of the world, but the onset of the main phytoplankton increase falls later in the year than in corresponding latitudes in northern hemispheres, especially towards the outer edge of the shelf. Dependent cycles of higher organisms are therefore also centred later in the year. This in turn affects the largest nekton (fish and squids) in that some at least show a similar 'lateness' in their biological seasons. Species, apparently corresponding to spring spawners elsewhere, spawn about mid-summer in this region, while hake, which in other regions are chiefly-summer spawners, ripen here mainly in autumn.

The second and larger part of the report deals mainly with the demersal fish fauna. It was found that the Patagonian continental shelf is notably poorer in species than are roughly comparable areas elsewhere. Two Merlucciidæ, a true hake (Merluccius hubbsi) and the 'long-tailed hake' (Macruronus magellanicus), were dominant among the larger fishes; and particular attention is devoted to them in the report, which deals in a detailed manner with the relative sizes of Patagonian and European hake, the distribution and relative abundance of Merluccius hubbsi within the area surveyed, the relationship between length and weight of this species and its value as an indicator of the spawning season, food and feeding, and the effect of latitude on numbers, size and sex ratio. Macruronus magellanicus is treated similarly, but slightly less fully, and the main features of the bionomics of the two species are summarized in a very useful table (p. 320).

The principal conclusion of the report is that, although the shelf is not very rich in trawlable fish, hake and some other edible species are present in moderate numbers. Unfortunately, the best trawling grounds are not very near the Falkland Islands.
Nevertheless, the report shows quite clearly that, on the shelf to the northward, roughly equidistant from the Falkland Islands and the lesser Argentine ports, there is a stock of hake just sufficient to enable a modern trawler to pay its way if there were markets equivalent to British ones within a few hundred miles. It is pointed out, however, that the population of the Falkland Islands is too small and too scattered to enable a suitable trawler to pay its way on local trade alone. Whether or not trawling can ever be developed would appear to depend, therefore, upon the growth of a demand for fish at an economic price in the Argentine as well as in the Falklands. Dr. Hart's report shows quite clearly that the raw material for the development of a trawl fishery, at any rate on a small scale, is present on the Patagonian shelf. It is now the task of the administrators and technologists to investigate and assess the prospects of exploiting them.

G. A. STEveN

\section{ASTRONOMICAL OBSERVATIONS IN AUSTRALIA}

$\mathrm{D}^{\mathrm{R}}$ R. R. v. d. R. WOOLLEY, Commonwealth Astronomer of australia, has issued a report covering the period January 1-December 31, 1947, the state of the Observatory at Canberra being represented on the latter date. The report includes the work carried out in fifteen different sections, and the following short summary deals with only a few of the main investigations that are described.

Under solar investigations are included, in addition to a description of the observational work, certain theoretical investigations. Baumbach's estimate of the electronic density in the corona has been recom. puted, allowances having been made for the scattering of the Fraunhofer coronal spectrum by dust and not by electrons, and it appears that the degree of ionization in the corona is caused by collisions with electrons at one million degrees C. In addition, the composition of the corona is shown to be similar to that of other cosmic sources, and the ratio of the number of hydrogen atoms to that of the metals is $6,000: 1$. The collision excitation crosssection of the coronal line has been measured by observation, and the coronal emission in discrete lines, and in continua has been computed. Under astronomical observations are included, among others, the following: the programme of observations of position angle and separation of double stars with the 9 -in. Oddie refractor; work on the determination of the stellar magnitudes of the sun, involving spectro. photometry of the light from a weakened solar image and from Sirius; variable-star investigations for which an electron-multiplier photometer was installed at the Farnham telescope and used to examine the light from several stars known to be spectroscopic variables, but which had not been reported as light variables; monochromatic photometry of brighter stars, using a commercial interference filter which, however, proved unsuitable, as it was transparent outside the nominal transmission band, and hence other methods were tried, as a result of which permanent apparatus for this work is now under construction; and the determination of stellar photometric gradients by using a slitless spectrograph for the Reynolds reflector. In connexion with this last programme, it is pointed out that, as the southern hemisphere is 